\title{
The effects of recombinant human DNase on neutrophil elastase activity and interleukin-8 levels in the sputum of patients with cystic fibrosis
}

\author{
P.L. Shah, S.F. Scott, R.A. Knight, M.E. Hodson
}

The effects of recombinant human DNase on neutrophil elastase activity and interleukin-8 levels in the sputum of patients with cystic fibrosis. P.L. Shah, S.F. Scott, R.A. Knight, M.E. Hodson. @eERS Journals Ltd 1996.

ABSTRACT: In cystic fibrosis (CF), neutrophil-dominated airway inflammation results in high levels of neutrophil elastase (NE). Some of these proteases are sequestered by the large amounts of deoxyribonucleic acid (DNA) present in purulent sputum. Recombinant human deoxyribonuclease (rhDNase), a new treatment in CF, depolymerizes DNA. Our concerns were that this might release proteases bound to DNA, which could be potentially harmful. The in vitro and in vivo effects of rhDNase on NE and interleukin-8 (IL-8) were evaluated.

The acute effects of rhDNase were evaluated in $\mathrm{CF}$ patients during the first 6 days of treatment. Medium-term effects were evaluated in stable CF patients observed on rhDNase over 6 months. Sputum samples were collected at regular intervals and NE activity was measured by a fluorimetric assay and IL-8 with a radioimmunoassay.

In vitro addition of rhDNase resulted in a twofold increase in protease activity and this was reflected in an acute transient rise on initiation of treatment with rhDNase. Medium-term treatment was associated with a decline in NE activity and IL-8.

These in vivo results are encouraging, since the increase in protease activity was transient and the trend over $\mathbf{6}$ months was a reduction in both inflammatory markers. Eur Respir J., 1996, 9, 531-534.
Dept of Cystic Fibrosis, Royal Brompton Hospital and National Heart \& Lung Institute, London, UK.

Correspondence: M.E. Hodson

Royal Brompton Hospital

Sydney Street

London SW3 6NP

UK

Keywords: Cystic fibrosis

inflammation

proteases

recombinant human deoxyribonuclease sputum

Received: January 191995

Accepted after revision November 221995
Impaired clearance and stasis of abnormally viscoelastic airway secretions in cystic fibrosis $(\mathrm{CF})$ contributes to bacterial colonization. This stimulates and perpetuates the detrimental inflammatory response, which is predominantly neutrophil-mediated. Neutrophil elastase (NE) released by the neutrophils degrades elastin, collagen and proteoglycans, and therefore causes damage to the lung [1-3]. The high levels of NE overwhelm the host antiprotease defence, damage epithelial cells by cleaving fibronectin [4], impair ciliary function [5, 6], and contribute to enhanced Pseudomonas aeruginosa adhesion in vitro [7], and in vivo [8]. NE also impairs successful opsonophagocytosis. It cleaves immunoglobulins [9], complement [10], and receptors on cell surfaces [11]. The NE-induced immuno-incompetence allows further bacterial persistence.

Following the process of "frustrated" phagocytosis, disintegrating neutrophils release large amounts of deoxyribonucleic acid (DNA) into the airway secretions [12]. The complexes formed between extracellular DNA and mucous glycoproteins further exacerbate the abnormal rheology of airway secretions in CF. NE is a potent secretagogue [13] and, therefore, further increases the quantity of viscous airway secretions. A further positive loop within the "vicious cycle" is due to induction of interleukin-8
(IL-8) expression by airway epithelial cells following exposure to NE [14]. IL-8 is a potent chemoattractant, which causes further neutrophil accumulation and promotes the inflammatory state [15].

Large polyanionic DNA polymers present in the purulent secretions electrostatically bind and sequester cationic proteases, such as NE [16]. Depolymerization of extracellular DNA may result in a reduction in the electrostatic binding and the liberation of proteases, including NE, which may be potentially harmful in CF. The aim of this study was to evaluate the effect of recombinant human deoxyribonuclease (rhDNase) both in vitro and in vivo on NE activity. IL-8 was used as a second marker for the inflammatory state, especially as it is not bound to polyanionic DNA molecules.

\section{Methods}

Sputum samples were collected over a $4 \mathrm{~h}$ period at a similar time of day before patients attended for their study visits. The samples were stored at $-20^{\circ} \mathrm{C}$ until analysed. A $0.66 \mathrm{~g}(\approx 0.5 \mathrm{~mL})$ aliquot of sputum was cut with a razor blade. After thawing, it was diluted with an equal volume of phosphate buffer and the mixture 
gently inverted a few times. Care was taken to minimize further cell lysis, which would result in the further release of proteolytic enzymes. The samples were then centrifuged at $20,000 \times \mathrm{g}$ and the sol phase obtained for analysis.

\section{Neutrophil elastase activity assay}

$\mathrm{NE}$ activity was measured by means of a fluorimetric assay based on a technique described by BARRETT [17]. The chromogenic peptide substrate was methoxysuccinylL-alanyl-L-alanyl-L-prolyl-L-valine 7-amino-4-methylcoumarin (Cambridge Research Biochemicals, Cambridge, UK). Sputum sol was diluted in $0.1 \%$ Triton (Tx-100) with $0.2 \mathrm{M}$ Tris $\mathrm{HCl}$ buffer at $\mathrm{pH} 8.5$, and then incubated with $20 \mu \mathrm{M}$ of the substrate for $10 \mathrm{~min}$ at $37^{\circ} \mathrm{C}$. The reaction was stopped with $0.1 \mathrm{mg}$ soyabean trypsin inhibitor (Sigma Chemicals, Poole, Dorset, UK) and the release of 7-amino-4-methylcoumarin (7AMC) measured at $460 \mathrm{~nm}$ on a fluorimeter (Perkins Elmer Model LS2B; Norwalk, CT, USA). The fluorimeter was calibrated with standards of 7AMC and the assay quantified with purified human neutrophil elastase standards (Sigma Chemicals, Poole, Dorset, UK). Enzyme units were defined as the release of $1 \mu \mathrm{mol}$ of the chromogen $\cdot \mathrm{min}^{-1} \cdot \mathrm{mL}$ of solubilized sputum at $37^{\circ} \mathrm{C}$. The sensitivity of the assay was 0.2 enzyme units, with a linear range of 0.5 20 enzyme units, and all samples were appropriately diluted prior to analysis.

\section{Interleukin-8 assay}

A radioimmunoassay (Advanced Magnetics, Cambridge, MA, USA) based on competitive inhibition between free IL-8 in the sample and radiolabelled IL-8 was used. Diluted samples in duplicate of the sol phase and recombinant IL-8 standards were incubated with a rabbit antiIL-8 antibody for a period of $24 \mathrm{~h}$ at room temperature. Radiolabelled IL-8 (125I-IL-8) was then added and the assay allowed to incubate for a further $4 \mathrm{~h}$. Bound IL8 was precipitated by a $20 \mathrm{~min}$ incubation with goat anti-rabbit immunoglobulin $\mathrm{G}(\mathrm{IgG})$ antibody. The samples were centrifuged at $5,000 \times \mathrm{g}$ at $4^{\circ} \mathrm{C}$ for $15 \mathrm{~min}$, the supernatant aspirated and the pellets washed twice with buffer. The pellets were counted in a calibrated automated gamma counter (Cobra Autogamma, Packard, Berkshire, UK). The percentage of bound ${ }^{125} \mathrm{I}-\mathrm{IL}-8$ was calculated for all standards and samples, a standard curve plotted, and the IL-8 concentration for each unknown sample determined by direct interpolation from the standard curve. The sensitivity of the IL- 8 assay was 0.068 $\mathrm{ng} \cdot \mathrm{mL}^{-1}$ with a linear range of $0.2-20 \mathrm{ng} \cdot \mathrm{mL}^{-1}$ and, therefore, all samples were diluted prior to analysis.

\section{In vitro experiment}

Sputum samples were obtained from 59 patients who were recruited into an open-label treatment study with
rhDNase. These pretreatment samples were divided into two $0.5 \mathrm{~mL}$ aliquots. One aliquot was incubated with $50 \mu \mathrm{g}$ rhDNase at $37^{\circ} \mathrm{C}$ for $30 \mathrm{~min}$. The sol phase was then obtained, as described previously, and NE and IL-8 levels measured both in treated and untreated samples.

\section{In vivo studies}

Short-term study. Nineteen patients were treated with rhDNase $2.5 \mathrm{mg}$ once daily, and sputum samples were obtained prior to treatment and daily for the first 6 days of therapy with rhDNase. These samples were obtained approximately 18-20 $\mathrm{h}$ after the last dose of rhDNase. Active NE was measured in the sol phase of the samples obtained.

Medium-term study. Fifty nine CF patients with mildto-moderate pulmonary disease (forced vital capacity $(\mathrm{FVC})>40 \%$ predicted) were treated with rhDNase 2.5 $\mathrm{mg}$ twice daily for 6 months [18]. Sputum samples were obtained from these patients on pretreatment (Day 0), and on treatment days 28, 84 and 168. The samples were collected over a $4 \mathrm{~h}$ period, approximately $8-12 \mathrm{~h}$ after the last dose of rhDNase. Patients who developed protocol defined respiratory tract infective exacerbations were excluded from the analysis, as previous studies have demonstrated that infection significantly increases levels of NE and IL-8 [19]. Respiratory tract infections were defined when four or more of the following features were present: decrease in forced expiratory volume in one second $(\mathrm{FEV} 1)>10 \%$; pyrexia $\left(>38^{\circ} \mathrm{C}\right)$; increased sputum production; increased dyspnoea; increased cough; malaise; new or increased haemoptysis; radiographic changes; or changes on auscultation.

\section{Statistical analysis}

The data was tested for normality and significant deviations were found. The results are, therefore, presented as medians (with interquartile ranges). Nonparametric analysis was performed on the data. The Wilcoxon matched pairs signed rank test was used to calculate the significance of results obtained following in vitro addition of rhDNase and for comparing the results between baseline and treatment day in the short-term study. Friedman's analysis was used to evaluate the effects over time (repeated measures in each individual). If the Friedman's analysis was significant then the significance between baseline and the other time-points (Days 28, 85 or 168) was evaluated by the Wilcoxon matched pairs signed rank test.

\section{Results}

In vitro experiment

Sputum samples were obtained from $59 \mathrm{CF}$ patients for assessment of in vitro effects of rhDNase. Median 
a)

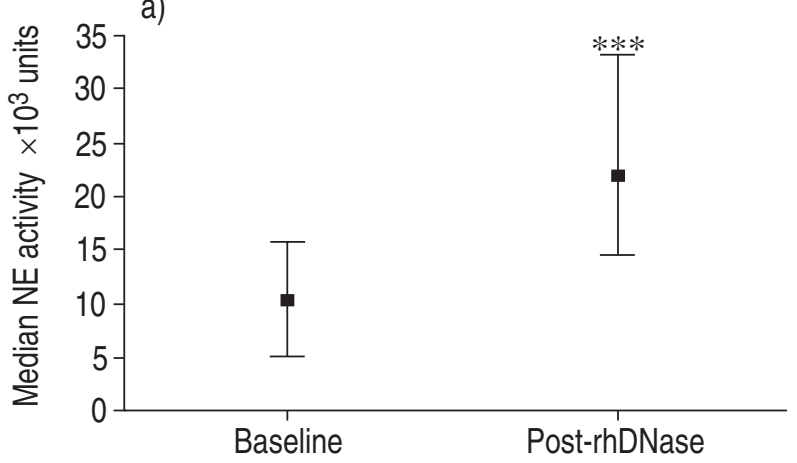

b)

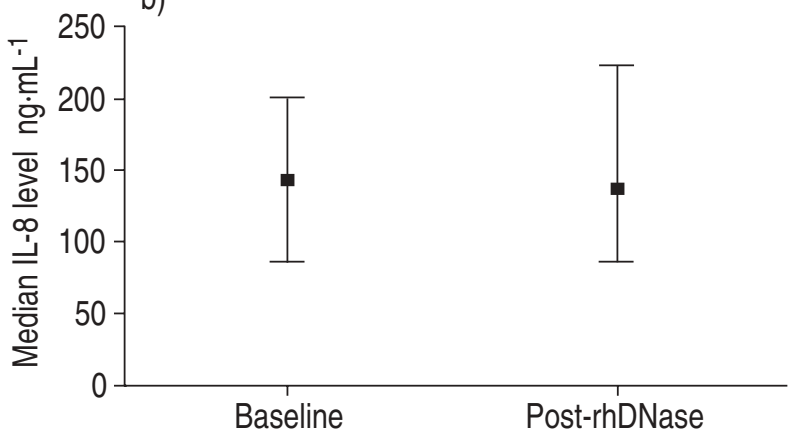

Fig. 1. - In vitro effects of rhDNase on sputum sol: a) neutrophil elastase activity; b) interleukin- 8 levels. $* * *: \mathrm{p}<0.001$. The horizontal bars represent interquartile range. rhDNase: recombinant human deoxyribonuclease; NE: neutrophil elastase; IL-8: interleukin-8.

baseline NE activity was $10.3(4.9-15.8) \times 10^{3}$ units, and incubation with rhDNase resulted in a significant $(\mathrm{p}<0.001)$ increase in protease activity (fig. 1a). The increase to $21.9(14.2-33.2) \times 10^{3}$ units represented a twofold increase. IL-8 levels were unaffected by in vitro treatment with rhDNase ( $\mathrm{p}=0.13$ ), (fig. $1 b)$.

\section{In vivo studies}

Short-term study. Initial therapy with rhDNase resulted in an increase in the protease burden. A peak in protease activity was observed after only one treatment with rhDNase ( $\mathrm{p}=0.018$ ), (fig. 2 ). Protease activity then

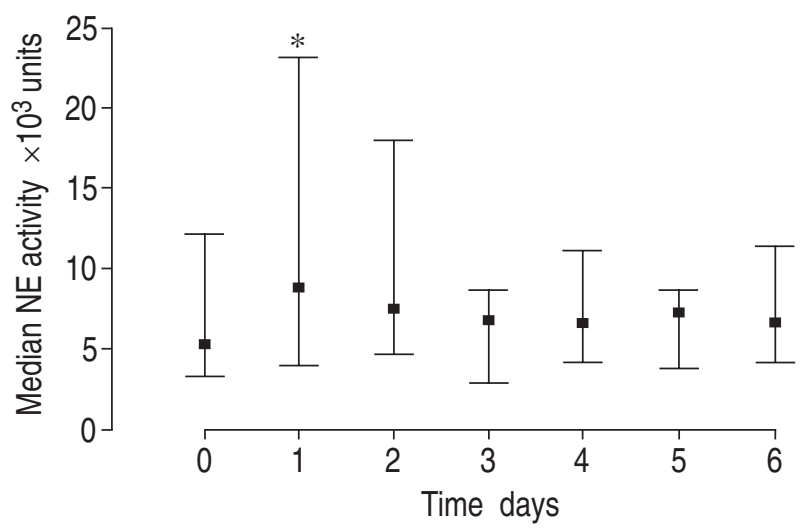

Fig. 2. - Short-term in vivo effects of rhDNase on sputum sol neutrophil elastase activity. *: $\mathrm{p}=0.018$. The horizontal bars represent interquartile range. For abbreviations see legend to figure 1. returned to previous levels over the next few days. However, there was considerable individual variation both in the time kinetics and the magnitude of the increase in protease activity.

Medium-term study. Nineteen CF patients developed respiratory tract infective exacerbations over a 6 month period. Baseline NE activity in the remaining $40 \mathrm{CF}$ patients was $9.6(4.9-16.2) \times 10^{3}$ units. No increase in protease activity was observed over the time-points evaluated in the stable patients, and at 6 months (Day 168) median NE activity was $6.7(3.4-14.6) \times 10^{3}$ units (fig. 3a). The significance of the overall variation was $\mathrm{p}=0.003$. IL-8 levels were also decreased from 140.9 (85.6-200.3) to $127.4(75.6-217.7) \mathrm{ng} \cdot \mathrm{mL}^{-1}$ at 6 months. However, the overall change was not statistically significant ( $\mathrm{p}=0.17$ ), (fig. 3b). No statistically significant correlation was found between the extent of decrease of elastase activity and of IL- 8 levels at the time-points evaluated.

Evaluation of all patients, including those with respiratory tract infections, confirmed that no increase in protease burden was observed over the 6 month period. Median NE activity was $10.3(5.0-15.4) \times 10^{3}$ units at baseline and $8.0(4.8-13.6) \times 10^{3}$ units at 6 months. The significance of the overall change was $\mathrm{p}<0.05$. However, these results are affected by the peaks in NE activity that occur due to infection.

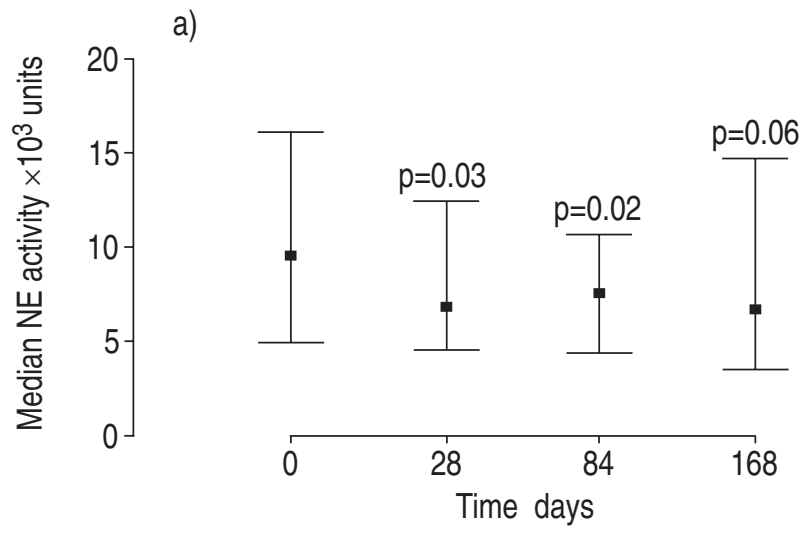

b)

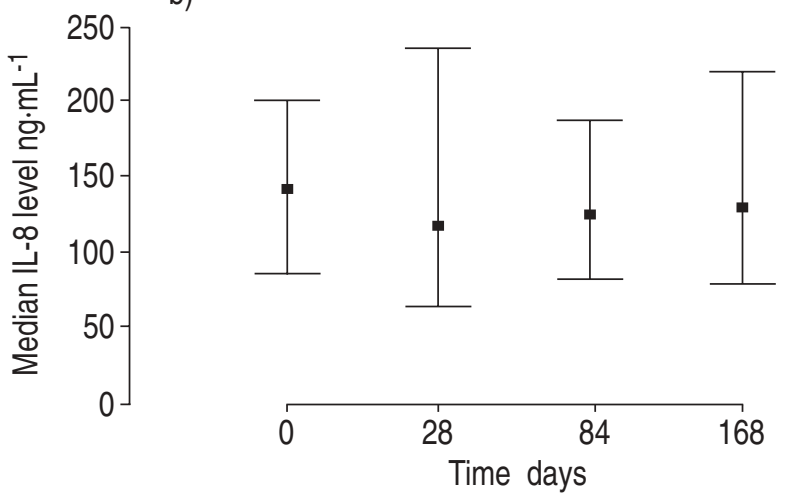

Fig. 3. - Serial sputum sol: a) neutrophil elastase activity; and b) interleukin-8 levels following medium-term treatment with rhDNase in vivo (excluding patients who developed respiratory tract infections). The horizontal bars represent interquartile range. For abbreviations see legend to figure 1 . 


\section{Discussion}

The addition of rhDNase to CF sputum in vitro resulted in an increase in NE activity. This effect was probably due to depolymerization of DNA and release of bound NE, rather than the effect of reducing viscoelasticity, because levels of IL-8, which is not bound to DNA, were unaffected. This increase in proteolytic activity in vivo was only observed on initiation of therapy. Indeed, longer-term therapy with rhDNase significantly reduced the proteolytic activity and resulted in a small, nonsignificant reduction in IL-8 levels. The reduction in viscoelasticity of airway secretions may improve clearance, and this effect may compensate for any acute local increases in proteolytic activity. However, the overall reduction in protease burden was small and the residual levels of NE and IL-8 remained very high.

The timing of the collection of samples may influence the results and if samples are collected soon after aerosolization of rhDNase then higher levels of protease activity are likely to be observed. However, the aim of the study was to evaluate the overall effect and, therefore, samples were collected 8-12 h post-treatment with rhDNase. Twenty four hour sputum collections are an alternative but may be confounded by incomplete collections. Moreover, the storage of sputum at room temperature for more than $6 \mathrm{~h}$ results in further increases in neutrophil elastase activity, which may be due to lysis of neutrophils.

A reduction in the protease burden may have some potential benefits. Proteolytic destruction of the lung architecture may be reduced. Reduction in degradation of opsonins and their receptors may improve opsonophagocytosis. This may allow improved bacterial clearance and may be one of the factors contributing to the reduction in bacterial colony counts observed following treatment with rhDNase [20].

The in vivo results are reassuring because the increase in protease activity due to depolymerization of DNA only has a transient effect and a decline in the protease burden may occur over the longer-term.

Acknowledgements: The authors thank J. Turner (medical statistician) for assistance with statistics.

\section{References}

1. Janoff A, White R, Carp H, Harel S, Dearing R, Lee D. Lung injury induced by leucocyte proteases. Am J Pathol 1979; 97: 111-136.

2. Starkey PM, Barrett AJ. Human lysosomal elastase: catalytic and immunological properties. Biochem J 1976; 155: 265-271.

3. Bruce MC, Poncz L, Klinger JD, et al. Biochemical and pathologic evidence for proteolytic destruction of lung connective tissue in cystic fibrosis. Am Rev Respir Dis 1985; 132: 529-535.

4. Suter S, Schaad UB, Morgenthaler JJ, Chevallier I, Schnebli HP. Fibronectin-cleaving activity in bronchial secretions of patients with cystic fibrosis. J Infect Dis 1988; 158: 89-100.

5. Smallman LA, Hill SL, Stockley RA. Reduction of ciliary beat frequency in vitro by sputum from patients with bronchiectasis: a serine proteinase effect. Thorax 1984; 39: 663-667.

6. Tegner H, Ohlsson K, Toremalm NG, Von Mecklenberg C. Effect of human leucocyte enzymes on tracheal mucosa and its mucociliary activity. Rhinology 1979; 17: 199206.

7. Woods DE, Straus DC, Johanson WG Jr, Bass JA. Role of fibronectin in the prevention of adherence of Pseudomonas aeruginosa to buccal cells. J Infect Dis 1981; 143: 784790.

8. Plotkwoski MC, Beck G, Tournier JM, Bernardo-Filho M, Marques EA, Puchelle E. Adherence of Pseudomonas aeruginosa to respiratory epithelium and the effect of leucocyte elastase. J Med Microbiol 1989; 30: 285-293.

9. Doring $\mathrm{G}$, Goldstein $\mathrm{W}$, Botzenhart $\mathrm{K}$, et al. Elastase from polymorphonuclear leucocytes: a regulatory enzyme in immune complex disease. Clin Exp Immunol 1986; 64: 597-605.

10. Orr FW, Varani J, Kreutzer DL, Senior RM, Ward PA. Digestion of the fifth component of complement by leukocyte enzymes: sequential generation of chemotactic activities for leukocytes and for tumour cells. Am J Pathol 1979; 94: 75-83.

11. Tosi MF, Zakem H, Berger M. Neutrophil elastase cleaves C3bi on opsonized Pseudomonas as well as CR1 on neutrophils to create a functionally important opsonin receptor mismatch. J Clin Invest 1990; 86: 300-308.

12. Lethem MI, James SL, Marriott C, Burke JF. The origin of DNA associated with mucus glycoproteins in cystic fibrosis sputum. Eur Respir J 1990; 3: 19-23.

13. Sommerhoff CP, Nadel JA, Basbaum CB, Coughey GH. Neutrophil elastase and cathepsin G stimulate secretion from cultured bovine airway gland serous cells. J Clin Invest 1990; 85: 682-689.

14. Nakamura H, Yoshimura K, McElvaney NG, Crystal RG. Neutrophil elastase in respiratory epithelial lining fluid of individuals with cystic fibrosis induces interleukin-8 gene expression in a human bronchial epithelial cell line. J Clin Invest 1992; 89: 1478-1484.

15. Richman-Eisenstat JB, Jorens PG, Hebert CA, Ueki I, Nadel JA. Interleukin-8: an important chemoattractant in sputum of patients with chronic inflammatory airway diseases. Am J Physiol 1993; 264: L413-L418.

16. Liberman J. Inhibition of protease activity in purulent sputum by DNA. J Lab Clin Med 1967; 70: 595-605.

17. Barrett AJ. Leucocyte elastase. Methods Enzymol 1981; 80: 581-588.

18. Shah PL, Scott S, Fuchs H, Geddes D, Hodson ME. Medium-term treatment of stable stage cystic fibrosis with recombinant human DNase I. Thorax 1994; 50: 333-338.

19. Shah PL, Scott SF, Knight RA, Hodson ME. The effect of respiratory tract infections on sputum sol phase elatase and interleukin-8 in cystic fibrosis patients. Proceedings of 19th European CF Conference 1994; p. 25 (Abstract).

20. Shah PL, Scott SF, Knight RA, Hodson ME. Quantitative changes in sputum microbiology following treatment of stable stage cystic fibrosis patients with aerosolised recombinant human DNase I. Pediatr Pulmonol 1993; (Suppl. 9): A232 (Abstract). 